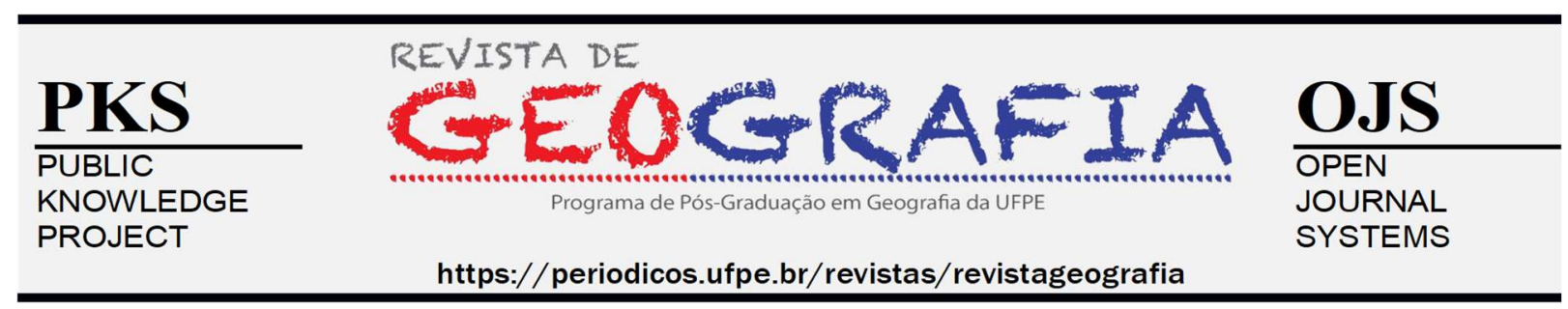

\title{
CONTRIBUIÇÃO DAS ÁREAS DE PROTEÇÃO AMBIENTAL NA CONSERVAÇÃO DO CERRADO
}

\author{
Ana Clara Alves de Meloํㅗ ${ }^{1}$ Patrick Thomaz de Aquino Martins² \\ ${ }^{1}$ Universidade Estadual de Goiás, Câmpus Nordeste - Sede: Formosa.E-mail: aanaclara_alves@hotmail.com \\ ${ }^{2}$ Universidade Estadual de Goiás, Câmpus Nordeste - Sede: Formosa. E-mail: patrick.tdäm@gmail.com
}

Artigo recebido em 28/09/2019 e aceito em 14/07/2020

\begin{abstract}
RESUMO: O estabelecimento de Unidades de Conservação (UCs) se faz importante à proteção da biodiversidade, principalmente em um momento em que se levantam discussões sobre os limites de exploração e alteração do meio ambiente devido aos usos antrópicos. Com o objetivo avaliar a efetividade de uma categoria de UC, a Área de Proteção Ambiental (APA), na conservação do Cerrado, o presente trabalho utilizou dados georreferenciados, do Ministério do Meio Ambiente e do projeto MapBiomas, para comparar, em diferentes anos, percentuais das classes de uso e cobertura da terra de 14 APAs, distribuídas majoritariamente no estado de Goiás e no Distrito Federal. Observou-se que, dentre as APAs avaliadas, 8 tiveram as áreas ocupadas pela cobertura de Cerrado reduzidas, 3 acrescidas e 3 permaneceram com o mesmo percentual. Embora a maioria das APAs tenha perdido área de Cerrado, é plausível afirmar, apoiado na acurácia intrínseca à metodologia de obtenção dos dados e na comparação da redução desta classe no próprio bioma, que as APAs estão cumprindo com o seu objetivo de compatibilizar a conservação da natureza com o uso sustentável dos recursos naturais.
\end{abstract}

Palavras-chave: Unidade de Conservação; Gestão; Atividades antrópicas; Análise temporal.

\section{CONTRIBUTION OF ENVIRONMENTAL PROTECTION AREAS IN THE CONSERVATION OF THE CERRADO}

\begin{abstract}
The establishment of Conservation Units (CUs) is important for the protection of biodiversity, especially at a time when arise discussions about the limits of exploration and alteration of the environment due to anthropic uses. In order to evaluate the effectiveness of a CU category, the Environmental Protection Areas (EPAs), in the conservation of the Cerrado, the present work used georeferenced data from the Ministry of the Environment and the MapBiomas project to compare, in different years, percentages of land use and land cover classes of 14 EPAs, distributed mostly in the state of Goiás and the Federal District. Among the evaluated EPAs, 8 had the areas occupied by Cerrado cover reduced, 3 increased and 3 remained with the same percentage. Although most EPAs have lost Cerrado area, it is plausible to say, supported by the intrinsic accuracy of the methodology for obtaining data and by comparing the reduction of this class in the biome itself, that APAs are fulfilling their goal of making conservation compatible with nature and the sustainable use of natural resources.

Keywords: Conservation Units; Management; Anthropic activities; Temporal analysis.
\end{abstract}




\section{INTRODUÇÃO}

O aumento das atividades humanas tem levantado discussões sobre os limites de exploração e alteração do meio ambiente devido aos usos antrópicos (OLSON et al., 2001; STEFFEN et al., 2015). As mudanças no uso da terra impactam diretamente as mudanças do clima, a integridade da biosfera, as alterações no ciclo biogeoquímico do fósforo e do nitrogênio, o uso da água doce (STEFFEN et al., 2015) e a biodiversidade, devido a disponibilidade de habitat e extinção de espécies (SALA et al., 2000).

Em virtude da sua dimensão e seu relevo, predominantemente plano e contínuo, o Cerrado foi palco das políticas públicas de ocupação na década de 1970 (BRASIL, 2015), que o levou a ser o segundo maior produtor agrícola e o principal exportador de soja do país (BRANNSTROM et al., 2008; JEPSON et al., 2005). Devido a essa expansão, o Cerrado já perdeu aproximadamente 56\% de sua cobertura de Cerrado (KLINK e MACHADO, 2005; SANO et al., 2010), sendo convertido, principalmente, em pastagens cultivadas (29,5\%), agricultura anual $(8,5 \%)$ e agricultura perene (3,1\%) (SANO et al., 2008; BRASIL, 2015).

Com a conversão de áreas naturais em atividades antrópicas, observou-se a alta fragmentação dos habitats naturais remanescentes do Cerrado, que interfere na manutenção e reprodução de espécies e em sua conservação (KLINK e MACHADO, 2005; CARVALHO et al., 2009; GARCIA et al. 2011). Dessa forma, devido às suas características ambientais e às pressões ocasionadas pela ocupação, o Cerrado foi inserido na lista de regiões prioritárias para conservação de diversidade biológica, sendo um dos hotspots mundiais (MYERS et al., 2000).

Um dos mecanismos que pode auxiliar a proteção da biodiversidade, possuindo o papel de conservar e preservar a natureza, é o estabelecimento de áreas protegidas em Unidades de Conservação (UCs). As UCs são espaços territoriais, com características naturais relevantes, para assegurar a manutenção das condições ecológicas e garantir as condições de perpetuação das espécies animais e vegetais (UICN, 1992; BRASIL, 2000). Neste sentido, as UCs possuem o papel de conservar e preservar a natureza.

No Brasil, as Unidades de Conservação dividem-se em dois grupos: (i) Unidades de Proteção Integral, cujo objetivo é preservar a natureza, sendo admitido apenas o uso indireto dos seus recursos naturais, com exceção dos casos previstos nesta Lei. São compostos pelas seguintes categorias: Estação Ecológica, Reserva Biológica, Parque Nacional; Monumento Natural e Refúgio de Vida Silvestre; e (ii) Unidades de Uso Sustentável, cujo objetivo é compatibilizar a conservação da natureza com o uso sustentável de parcela dos seus recursos 
naturais. São compostas por Área de Proteção Ambiental; Área de Relevante Interesse Ecológico; Floresta Nacional; Reserva Extrativista; Reserva de Fauna; Reserva de Desenvolvimento Sustentável; e Reserva Particular do Patrimônio Natural (BRASIL, 2000).

Atualmente, o Cerrado apresenta $8,21 \%$ de seu território legalmente protegido por Unidades de Conservação, sendo, desse total, 2,85\% constituídos por Unidades de Conservação de Proteção Integral, quantitativo que faz do Cerrado o bioma com a menor porcentagem de áreas sobre proteção integral dentre todos os hotspots mundiais (MMA, 2019).

Nesse contexto, o objetivo deste trabalho foi avaliar a efetividade das Áreas de Proteção Ambiental (APAs) na conservação da cobertura de Cerrado. Esta categoria de UC foi escolhida por permitir a existência das atividades humanas em seu interior, sendo a menos restritiva dentro do Sistema Nacional de Unidades de Conservação - SNUC (TEIXEIRA, 2005; ZANATTO, 2018).

\section{MATERIAL E MÉTODOS}

Área de estudo

Segundo o SNUC (BRASIL, 2000), a APA é uma área em geral extensa, com um certo grau de ocupação humana, e tem como objetivos básicos proteger a diversidade biológica, disciplinar o processo de ocupação e assegurar a sustentabilidade do uso dos recursos naturais.

Para a escolha das APAs a serem avaliadas (Figura 1), foram utilizados os dados vetoriais disponibilizados pelo Ministério do Meio Ambiente, obtido por meio da página eletrônica de sua biblioteca virtual (http://mapas.mma.gov.br/i3geo/datadownload.htm). Os critérios para a escolha das APAs levou em consideração estarem inseridas majoritariamente no estado de Goiás e no Distrito Federal e possuírem dados de uso e cobertura da terra para, pelo menos, um ano antes e um ano depois de sua criação.

Desta forma, das 19 APAs existentes nas referidas Unidades da Federação, 5 UCs não puderam ser avaliadas. Às APAs da Bacia do Rio Descoberto e da Bacia do Rio São Bartolomeu não foi possível obter dados anteriores à sua criação, a qual se deu em 1983. Já as APAs do Limoeiro, do Córrego da Lagoa e da Bacia do Córrego do Capão Grande foram criadas em 2017, não possuindo dados pretéritos durante à realização do trabalho. As 14 Unidades de Conservação que se enquadraram nos critérios de escolha adotados neste trabalho estão apresentadas na Figura 1. 

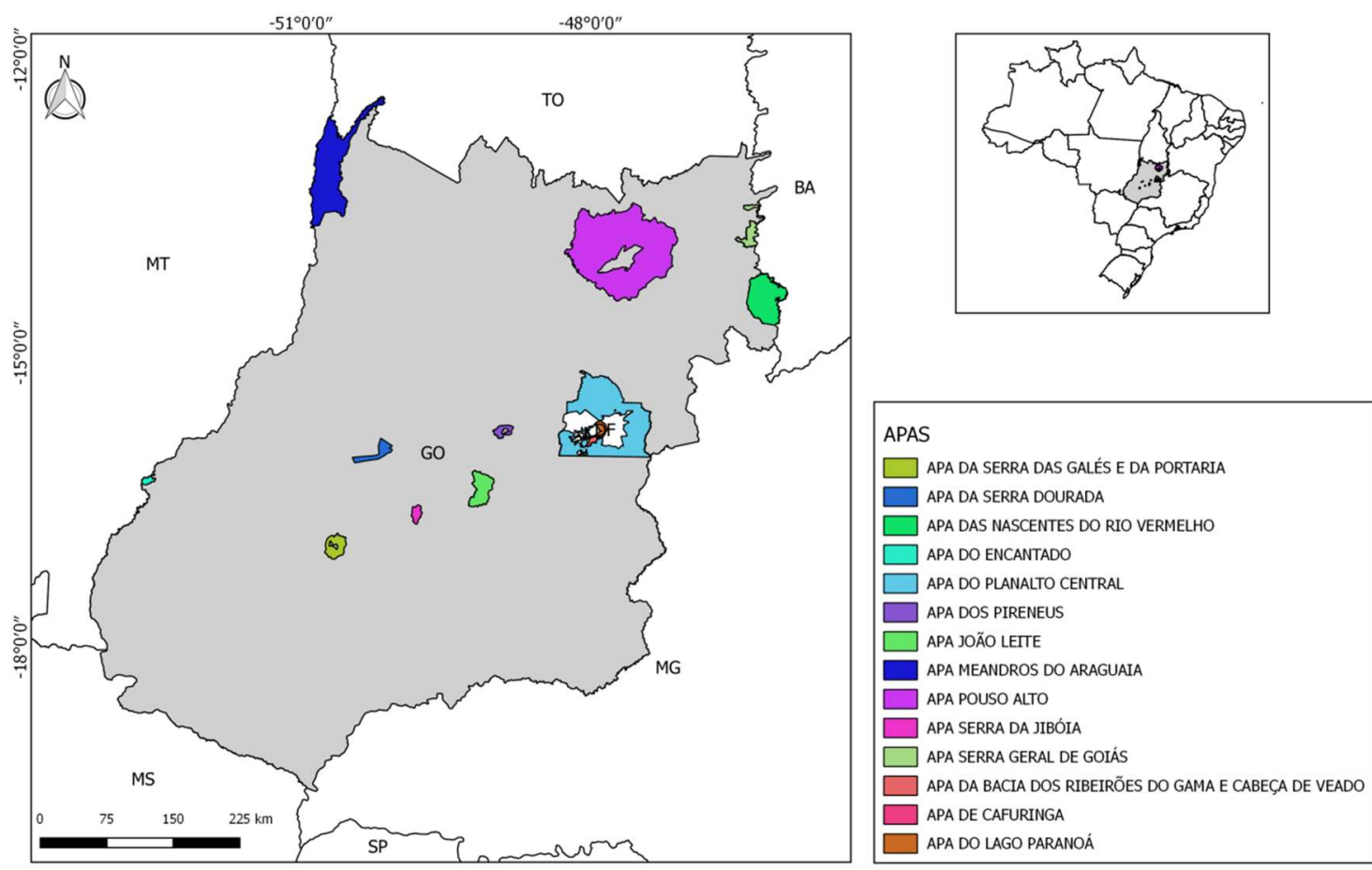

Figura 1. Mapa de localização das Unidades de Conservação em estudo.

\section{Estimativa de perda da área de Cerrado}

Para avaliar a efetividade das APAs na conservação da cobertura de Cerrado, foi mensurada, em cada UC selecionada, a área ocupada pelas classes de uso e cobertura da terra. Para tal, utilizou-se a base de dados do Projeto MapBiomas (http://mapbiomas.org/), que disponibiliza, via Google Earth Engine, o mapeamento de uso e cobertura da terra do Brasil para o período de 1985 a 2017. Foram avaliados anos que compreendessem períodos antes, durante e após o estabelecimento das Áreas de Proteção Ambiental, buscando, sempre que possível, a manutenção do interstício de cinco anos. Deste modo, cada APA possui intervalo singular de observação.

\section{RESULTADOS E DISCUSSÃO}

As informações sobre as UCs, tais como esferas, ano de criação, ato legal, órgão responsável e área podem ser visualizadas na Tabela 1. Nesta, pode-se observar que, das 14 APAs avaliadas, apenas 3 são de esfera federal.

As classes temáticas identificadas nas UCs foram: (i) Cerrado (agrupamento que compreende as formações savânicas, campestres, florestal e outras formações não florestais); (ii) agricultura - semi-perene, anual e perene (áreas de solo exposto ou vegetadas geralmente 
compostas por uma única espécie de interesse comercial); (iii) pastagem (áreas geralmente compostas por uma única espécie de gramíneas - Brachiaria, com diferentes proporções de rebrota e/ou exposição de solo, dependendo do nível de degradação); (iv) mosaico de agricultura e pastagem (quando não há uma diferenciação clara entre agricultura e pastagem); (v) infraestrutura urbana; e (vi) rio, lago (BRASIL, 2015; PROJETO MAPBIOMAS, 2019).

A APA do Encantado está localizada no município de Baliza-GO, é de esfera estadual e foi criada em 2003 (Tabela 1). Antes da criação da APA do Encantado, houve uma pequena perda, de $2 \%$, da cobertura de Cerrado. No entanto, após a sua criação, esta classe se recompôs, havendo um crescimento de 3\%. Assim, no período de 1985 a 2017, não obstante a pequena dinâmica apresentada, o quantitativo da classe de cobertura de Cerrado nessa APA se manteve homólogo, com 93\% ao longo do período (Figura 2A), observando-se, no entanto, uma tendência no crescimento das áreas de pastagens.

A APA de João Leite abrange sete municípios do estado de Goiás: Ouro Verde de Goiás, Campo Limpo de Goiás, Anápolis, Teresópolis de Goiás, Nerópolis, Goiânia e Goianápolis. Após a criação desta APA, que é de esfera estadual, em 2002 (Tabela 1), houve perda de 3\% de cobertura de Cerrado, as quais foram convertidas em pastagem e agricultura. Se no início do período analisado, 1985, essa APA apresentava 43\% de cobertura de Cerrado, em 2017 a predominância é de pastagem, $40 \%$ da APA, com tendência de aumento desta classe (Figura 2B).

Santos et al. (2018), em estudo realizado no Reservatório do Ribeirão João Leite, constataram que pelo menos $40 \%$ da cobertura original foi convertida em algum tipo de atividade antrópica, sendo que as pastagens foram as que apresentaram o maior potencial de modificação da paisagem. Os autores argumentaram, ainda, que este fato reflete a expansão das fronteiras agropecuárias do estado de Goiás, transformando-o em uma das maiores potências do país, em detrimento da proteção e conservação de seus recursos naturais.

Para Sousa (2013), é importante estabelecer uma conexão entre a preservação e a utilização, pois a produção desta área não pode ser afetada pelas limitações de uso impostas pela APA. O autor afirma, ademais, a necessidade de uma gestão integrada para a área. 
Tabela 1. Informações técnicas sobre as Unidades de Conservação.

\begin{tabular}{|c|c|c|c|c|}
\hline NOME & ESFERA & CRIAÇÃO & ORGÃO RESPONSÁVEL & ÁREA (HA) \\
\hline APA de Cafuringa & distrital & 1988 & 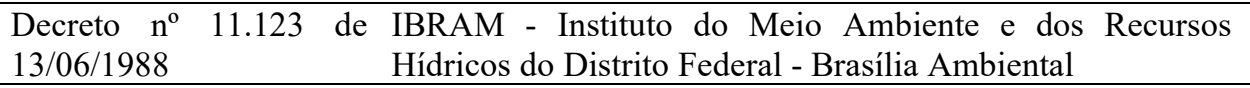 & $46.589,762$ \\
\hline APA do Encantado & estadual & 2003 & $\begin{array}{ll}\begin{array}{l}\text { Lei ordinária } \mathrm{n}^{\circ} 14.386 \text { de } \\
13 / 01 / 2003\end{array} & \text { SEMAD - Secretaria de Estado de Meio Ambiente e } \\
\text { Desenvolvimento Sustentável - Goiás } & \end{array}$ & $9.443,929$ \\
\hline APA João Leite & estadual & 2002 & $\begin{array}{lllll}\begin{array}{l}\text { Decreto } \\
n^{0}\end{array} \text { 5.704 de } & \text { SEMAD - Secretaria de Estado de Meio Ambiente e } \\
& \text { Desenvolvimento Sustentável - Goiás }\end{array}$ & $71.357,843$ \\
\hline APA do Lago Paranoá & distrital & 1989 & $\begin{array}{lllll}\begin{array}{l}\text { Decreto } \mathrm{n}^{\mathrm{o}} \\
15 / 12 / 1989\end{array} & & & \text { de } & \text { IBRAM - Instituto do Meio Ambiente e dos Recursos } \\
15 / 12 / 198 & & \text { Hídricos do Distrito Federal - Brasília Ambiental } & \\
\end{array}$ & $16.104,249$ \\
\hline APA Meandros do Araguaia & federal & 1998 & $\begin{array}{lcccl}\begin{array}{l}\text { Decreto } \mathrm{n}^{\mathrm{o}} \\
02 / 10 / 1998\end{array} & \mathrm{~S} / \mathrm{N} \text { de } \begin{array}{l}\text { ICMBio - Instituto Chico Mendes de Conservação da } \\
\text { Biodiversidade }\end{array}\end{array}$ & $358.916,224$ \\
\hline $\begin{array}{l}\text { APA das Nascentes do Rio } \\
\text { Vermelho }\end{array}$ & federal & 2001 & $\begin{array}{l}\begin{array}{l}\text { Decreto } \mathrm{n}^{0} \\
28 / 09 / 2001\end{array} \\
\end{array}$ & $177.384,442$ \\
\hline APA dos Pireneus & estadual & 2000 & $\begin{array}{lllll}\begin{array}{l}\text { Decreto } \\
\mathrm{n}^{\circ}\end{array} \text { 5.174 } & \text { de } & \text { SEMAD - Secretaria de Estado de Meio Ambiente e } \\
& \text { Desenvolvimento Sustentável - Goiás }\end{array}$ & $19.192,878$ \\
\hline APA Pouso Alto & estadual & 2001 & $\begin{array}{lllll}\begin{array}{l}\text { Decreto } \\
n^{\circ}\end{array} \text { 5.419 de } & \text { SEMAD - Secretaria de Estado de Meio Ambiente e } \\
& \text { Desenvolvimento Sustentável - Goiás }\end{array}$ & $841.568,503$ \\
\hline APA do Planalto Central & federal & 2002 & $\begin{array}{llll}\begin{array}{l}\text { Decreto } \mathrm{n}^{\mathrm{o}} \\
10 / 01 / 2002\end{array} & \mathrm{~s} / \mathrm{n} & \text { de } \begin{array}{l}\text { ICMBio - Instituto Chico Mendes de Conservação da } \\
\text { Biodiversidade }\end{array} \\
\end{array}$ & $504.512,182$ \\
\hline $\begin{array}{l}\text { APA das Bacias Gama e Cabeça } \\
\text { de Veado }\end{array}$ & distrital & 1986 & $\begin{array}{lccccc}\begin{array}{l}\text { Decreto } \\
\mathrm{n}^{\circ}\end{array} & 9.417 & \text { de } & \text { IBRAM - Instituto do Meio Ambiente e dos Recursos } \\
24 / 04 / 1986\end{array}$ & $23.786,306$ \\
\hline $\begin{array}{l}\text { APA da Serra das Gales e da } \\
\text { Portaria }\end{array}$ & estadual & 2002 & $\begin{array}{lcccc}\begin{array}{l}\text { Decreto } \\
\mathrm{n}^{0}\end{array} \text { 5.573 de } & \begin{array}{l}\text { SEMAD - Secretaria de Estado de Meio Ambiente e } \\
\text { 22/03/2002 }\end{array} & & \text { Desenvolvimento Sustentável - Goiás }\end{array}$ & $46.249,944$ \\
\hline APA da Serra Dourada & estadual & 1998 & $\begin{array}{lllll}\begin{array}{l}\text { Decreto } \\
17 / 02 / 1998\end{array} & 4.866 & \text { de } & \begin{array}{l}\text { SEMAD - Secretaria de Estado de Meio Ambiente e } \\
\text { Desenvolvimento Sustentável - Goiás }\end{array} \\
\end{array}$ & $37.017,196$ \\
\hline APA da Serra Geral de Goiás & estadual & 1996 & $\begin{array}{lllll}\begin{array}{l}\text { Decreto } \\
\text { 22/04/1996 }\end{array} & 4.666 & \text { de } & \begin{array}{l}\text { SEMAD - Secretaria de Estado de Meio Ambiente e } \\
\text { Desenvolvimento Sustentável - Goiás }\end{array} \\
\end{array}$ & $44.394,074$ \\
\hline APA Serra da Jiboia & estadual & 2000 & $\begin{array}{lllll}\begin{array}{l}\text { Decreto } \\
\text { 03/03/2000 }\end{array} & 5.175 & \text { de } & \begin{array}{l}\text { SEMAD - Secretaria de Estado de Meio Ambiente e } \\
\text { Desenvolvimento Sustentável - Goiás }\end{array} \\
\end{array}$ & $17.155,14$ \\
\hline
\end{tabular}

Fonte: Ministério do Meio Ambiente (2019). 


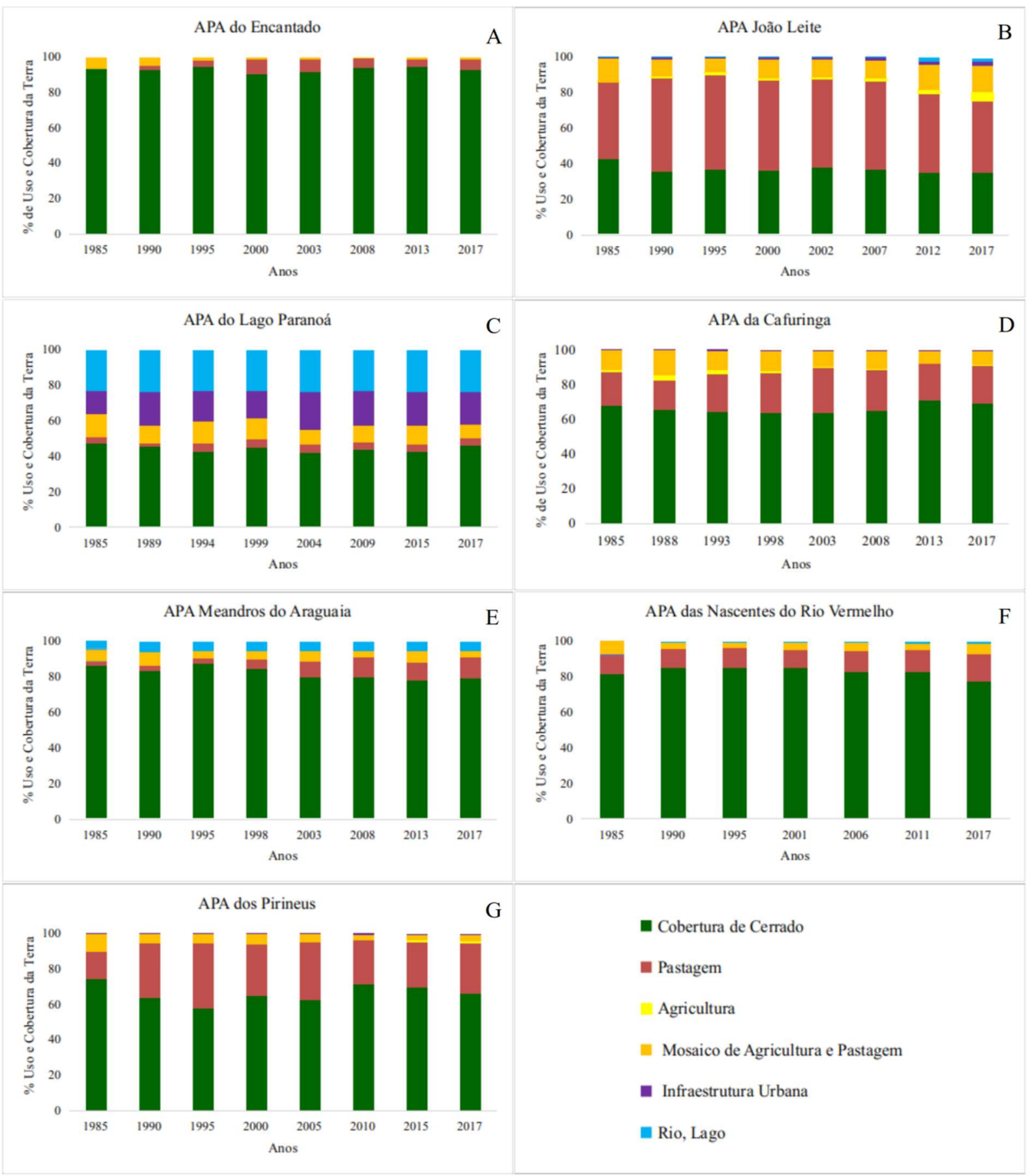

Figura 2. Evolução temporal do uso e cobertura da terra entre os anos de 1985 e 2017 da APA do Encantado (A), da APA João Leite (B), da APA do Lago Paranoá (C), da APA da Cafuringa (D), da APA Meandros do Araguaia (E), da APA das Nascentes do Rio Vermelho (F) e da APA dos Pirineus (G).

Fonte: Projeto MapBiomas (2019).

A APA do Lago Paranoá é de esfera distrital e, como tal, está localizada no Distrito Federal. Antes da sua criação, que ocorreu em 1989 (Tabela 1), é possível observar que a cobertura de Cerrado totalizava 47\% da área. Em 1994 e 2015 a APA teve uma redução no 
percentual desta cobertura em 4\%. Em 2017 houve recuperação parcial deste quantitativo, chegando a 46\%. Destaca-se que as áreas de agropecuária permaneceram com o mesmo percentual de ocupação até o ano de 2017 (11\%). No entanto, em 1994 e 1999 foi apresentado um pico dessa atividade na APA, principalmente a pastagem, com 12\% (Figura 2C).

Observa-se, ainda, que a classe de infraestrutura urbana se manteve praticamente constante ao longo dos anos. Dias e Walde (2013) constataram que as principais transformações ocorreram no sentido de urbanização do território, confirmando a tendência de crescimento urbano do Distrito Federal.

Chama a atenção, nesta APA, além da expressiva presença da infraestrutura urbana, maior entre as UCs selecionadas para este trabalho, a aparente redução do percentual desta classe em alguns anos, causando pequenas flutuações no quantitativo desta classe ao longo do período avaliado. Este decréscimo, pouco habitual, pode estar associado à uma imprecisão na acurácia temática intrínseca à metodologia de mapeamento (JANSSEN; VAN DER WEL, 1994), a qual, nos dados utilizados neste trabalho, gira em torno de 75\% (PROJETO MAPBIOMAS, 2019).

Entre as classes de pastagem cultivada e de formação campestre do Cerrado, por exemplo, há pouca diferença espectral (SANO et al., 2007), resultante da predominância de espécies gramíneas em ambas as classes (SILVA; SANO, 2016). Esta semelhança dificulta a separabilidade das classes e pode resultar em baixa acurácia do mapeamento por classificação de imagens de sensoriamento remoto, como a utilizada nos dados utilizados neste trabalho.

A APA da Cafuringa, de esfera distrital, possui 46.589,762 ha de área (Tabela 1) e está sobreposta a APA do Planalto Central. Ao longo de 33 anos, a área de Cerrado teve 1\% de ganho, apresentando, entretanto, variações durante este período. Em 2013 a APA apresentou $71 \%$ desta cobertura. Após a sua criação, em 1988, a APA perdeu 2\% de Cerrado, que foram convertidas em agropecuária. Depois de 5 anos de sua criação, em 1993, a APA continuou perdendo cobertura de Cerrado (1\%), sendo convertida, principalmente, em áreas de pastagem. No entanto, em 2017, esta UC apresentou $69 \%$ de cobertura de Cerrado, $4 \%$ a mais que no ano de sua criação (Figura 2D).

Nesta mesma APA, Fortes et al. (2007) identificaram uma tendência de supressão de áreas com cobertura vegetal nativa em virtude do crescimento de áreas de reflorestamento, agrícolas e urbanas. Embora o crescimento da área de Cerrado em um curto espaço de tempo (e.g. de 2008 a 2013, na APA da Cafuringa) possa estar relacionado à, já citada, imprecisão na 
acurácia temática, se faz necessário informar que também pode estar associado ao processo de recuperação da vegetação. Esta recuperação pode ser facilitada, em boa parte dos casos, pela capacidade da vegetação do Cerrado de rebrotar inúmeras vezes após distúrbios (DURIGAN et al. 2011). Em áreas afligidas pelo fogo, por exemplo, Alves et al. (2018) identificaram, utilizando técnicas de sensoriamento remoto, que o vigor vegetal pode retornar aos mesmos níveis, de antes da ocorrência da perturbação, após três anos.

Criada em 1998, a APA Meandros do Araguaia, uma UC de esfera federal (Tabela 1), possuía 84\% de área de Cerrado antes de sua criação, passando a cerca de 79\% em 2017 (Figura 2E), sendo, a área perdida, convertida em pastagem. Esta APA apresenta área em mais de uma Unidade Federativa, se fazendo presente nos municípios de São Miguel do Araguaia e Nova Crixás, no estado de Goiás, Cocalinho, Novo Santo Antônio, no estado do Mato Grosso, e Formoso do Araguaia, no Tocantins.

Embora as alterações ocorridas nesta APA possam ser identificadas como significativas (SANTOS et al., 2011), as coberturas de Cerrado ainda predominam sobre os demais tipos de uso, condição que, de acordo com Santos e Romão (2007), pode indicar grande potencial à recuperação.

À semelhança da APA Meandros do Araguaia, a APA das Nascentes do Rio Vermelho também apresenta área em mais de uma UF, sendo, deste modo, de esfera federal (Tabela 1). A APA, cuja decreto de criação se deu em 2001, intersecta os municípios goiano de Posse, Buritinópolis, Mambaí e Damianópolis e do município de Jaborandi, na Bahia. Em 1985, a área onde futuramente seria a UC possuía $82 \%$ de cobertura de Cerrado, percentual que, em 2001, aumentou para $85 \%$ e, em 2017, diminuiu a 77\% (Figura 2F). Ou seja, após a criação da UC houve perda de $8 \%$ de cobertura de Cerrado, a qual foi convertida em atividades agropecuárias (21\%) (Figura 2F). Mesmo com predomínio da cobertura de Cerrado, Miranda (2016) observou um aumento de áreas degradadas, podendo estas estarem relacionadas às atividades agropecuárias realizadas no Oeste Baiano.

A APA dos Pireneus é de esfera estadual e foi criada em 2000, com uma área de aproximadamente 19.193 ha (Tabela 1). Está localizada nos municípios de Cocalzinho de Goiás, Pirenópolis e Corumbá de Goiás. Anos antes de sua criação, em 1985, a área apresentava $74 \%$ de cobertura de Cerrado. No ano de implementação do Parque, essa cobertura ocupava 65\% da área da APA. Já em 2017 foi identificado acréscimo de 1\%, totalizando 66\% (Figura $2 \mathrm{G})$. Em contrapartida, as atividades agropecuárias tiveram um crescimento de $13 \%$ até o ano 
2000, passando de 16\% para 29\%. Em 2017 houve uma redução de 2\%, totalizando 33\% de cobertura antrópica (Figura 2G).

Salmona et al. (2014) também observaram que as atividades agropecuárias passaram a ocupar áreas de cobertura de Cerrado. Os autores afirmaram que a perda de cobertura de Cerrado na APA é uma grave ameaça à efetividade do Parque dos Pireneus. Além disso, os autores foram categóricos ao afirmarem que, com a constante e intensa supressão de áreas nativas e com o acelerado ritmo de desmatamento, é provável que não haja muitas opções de áreas para se proteger essa cobertura em um futuro próximo.

A APA do Pouso Alto, criada em 2001, possui uma área de cerca de 841.569 ha (Tabela 1) distribuída nos municípios de Cavalcante, Colinas do Sul, Alto Paraíso de Goiás, Nova Roma, Teresina de Goiás, São João d'Aliança, todos no estado de Goiás. Esta APA possui, inserida em seu interior, outra UC, esta de Proteção Integral, o Parque Nacional da Chapada dos Veadeiros.

Em 1985 a área destinada a APA apresentava 91\% de cobertura de Cerrado. No seu ano de criação esta classe ocupava 86\%, passando, em 2017, para 87\% (Figura 3A). De acordo com Zardini et al. (2016), diferentes fatores, tais como relevos predominantemente ondulados (fator físico/ambiental), o lento processo de ocupação da região (fator histórico e cultural), o desenvolvimento do ecoturismo (fator econômico) e a criação de áreas de preservação cultural e ambiental (fator político) contribuíram e contribuem para a preservação do Cerrado nesta região, o que pode explicar o baixo incremento de classes agropecuárias (Figura 3A) na APA durante o período aqui avaliado.

Para Ferreira e Almeida (2014), mesmo que a região em que a APA está localizada seja a mais preservada do Cerrado goiano, a criação e consequente implementação da APA do Pouso Alto esteve vinculada a conflitos de interesses de diversos atores. Os autores afirmam que a conclusão do Plano de Manejo da APA do Pouso Alto representará um ordenamento no uso de sua área, indicando as ações a serem desenvolvidas, o que proporcionará a compatibilização dos usos que atendam a necessidade do desenvolvimento econômico da região aliado ao compromisso da preservação da natureza. Além disso, eles sustentam a necessidade de um diálogo entre os atores em busca de união entre dois pontos fundamentais: desenvolvimento local e a preservação da biodiversidade, o que se configura em um dos principais objetivos da APA. 
A APA do Planalto Central, criada em 2002 (Tabela 1), está localizada no Distrito Federal e nos municípios de Planaltina e Padre Bernardo, estado de Goiás, sendo, assim, de esfera federal. Em 1985 a área que seria transformada em UC apresentava 62\% de Cerrado (Figura 3B). Dois anos antes do estabelecimento da APA, em 2000, o percentual foi de 57\%, i.e., houve uma perda de 5\% nessa cobertura. Este percentual se manteve em equilíbrio ao longo dos anos, com um pico em 2012, com 59\% de cobertura de Cerrado. O percentual remanescente foi, quase que totalmente, compreendido pelo uso agropecuário (Figura 3B), o que pode ser explicado pela composição do relevo, mais plano, que se apresenta como um facilitador na utilização do maquinário agrícola, favorecendo assim sua expansão, e englobar solo favorável a agricultura, como é o Latossolo, com boa permeabilidade (GOIS, 2017).

A APA das Bacias Gama e Cabeça de Veado, localizada no Distrito Federal, é de esfera distrital. Foi criada em 1986 e possui uma área de 23.786,306 ha (Tabela 1). No período de 1986 a 2017 a cobertura de Cerrado cresceu 2\%, passando de 78\% para 80\% (Figura 3C). As coberturas agropecuárias (agricultura, pastagem e mosaico de agricultura e pastagem) reduziram de $18 \%$ para $14 \%$ nesse mesmo período. Além disso, a infraestrutura urbana aumentou 2\% (Figura 3C). Esses dados corroboram com os obtidos por Machado et al. (2008), que afirmaram que todo o perímetro da APA e sua zona de amortecimento apresentaram alteração das condições naturais do ambiente.

A APA da Serra das Gales e da Portaria está localizada no município de Paraúna, estado de Goiás. É de esfera estadual e foi criada em 2002 (Tabela 1), momento em que a cobertura de Cerrado recobria 36\% da UC (Figura 3D). Anteriormente, o percentual chegou a ser de cerca de $45 \%$, havendo, deste modo, até a criação da APA, perda de 9\% de área de Cerrado (Figura 3D). Mesmo com recuperação de 1\% desta cobertura após a sua criação, ao longo de 33 anos (1985 a 2017) a APA perdeu, pelo menos, 8\% de cobertura de Cerrado, a qual foi convertida em coberturas associadas à agropecuária (Figura 3D). No último ano de registro, cerca de 63\% desta UC foi utilizada para fins agropecuários, sendo 31\% de pastagem, 28\% de agricultura e $4 \%$ de mosaico de agricultura e pastagem (Figura 3D).

Nota-se que, antes mesmo da criação da UC, já havia um processo intenso de atividades agropecuárias, com foco nas áreas de pastagens. Uma possível explicação para esta questão é o fato de a APA estar perto de grandes polos agropecuários, como o observado por Sano et al. (2006), o que reflete diretamente na sua zona de amortecimento e no seu interior. 


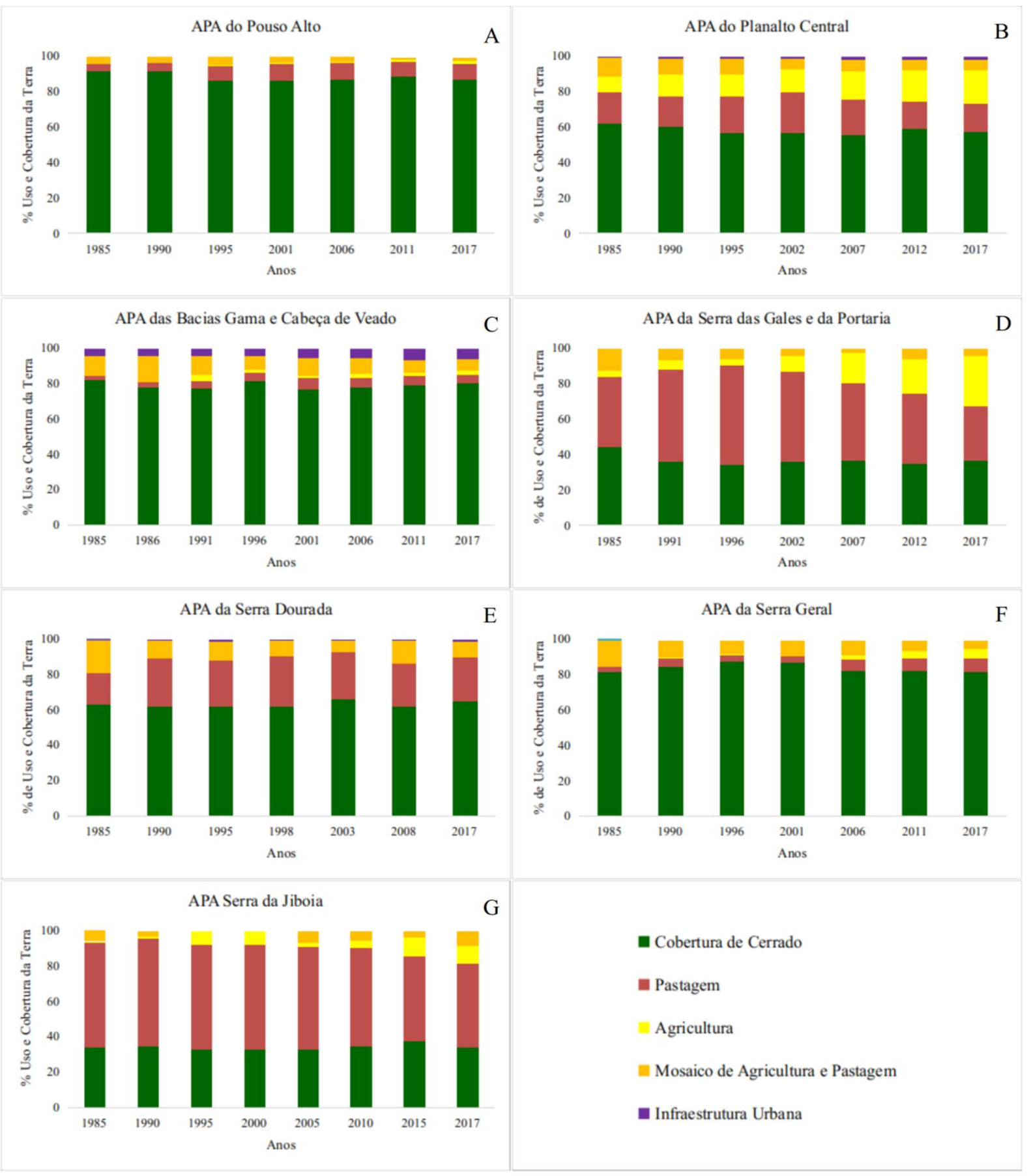

Figura 3. Evolução temporal do uso e cobertura da terra entre os anos de 1985 e 2017 da APA do Pouso Alto (A), da APA do Planalto Central (B), da APA das Bacias Gama e Cabeça de Veado (C), da APA da Serra das Gales e da Portaria (D), da APA da Serra Dourada (E), da APA da Serra Geral (F) e da APA Serra da Jiboia (G).

Fonte: Projeto MapBiomas (2019).

A APA da Serra Dourada, localizada nos municípios de Goiás, Mossâmedes e Buriti de Goiás, é uma UC estadual criada em 1998 (Tabela 1). Antes da sua criação, a APA possuía cerca de $63 \%$ de cobertura de Cerrado (Figura 3E). No ano de sua criação esta classe ocupava 
62\%, subindo para 65\% em 2017. Destaca-se, que as áreas agropecuárias passaram de 36\%, em 1985, para 34\%, em 2017, correspondendo, deste modo, ao aumento de cobertura de Cerrado e diminuição das áreas antrópicas (Figura 3E).

A APA Serra da Jiboia, criada em 2000, é de esfera estadual (Tabela 1) e está localizada em Nazário e Palmeiras de Goiás. Em 1985, 15 anos antes da sua criação, a área a qual seria a APA apresentava 34\% da classe cobertura de Cerrado (Figura 3F). Em 2000 esse percentual foi reduzido para 33\% e em 2017 voltou aos 34\%, sendo que em 2015, o Cerrado recobriu 38\% da UC (Figura 3F).

A APA da Serra Geral de Goiás é de esfera estadual, criada em 1996, e possui em torno de 44.394 ha (Tabela 1). Está localizada nos municípios de São Domingos e Guarani de Goiás. Em observação a anos anteriores à sua criação, é possível constatar que a APA tinha $81 \%$ de área de Cerrado (Figura 3G), ao passo que, no ano de sua criação, esse percentual subiu para $87 \%$. No entanto, em 2017 , este diminuiu para $81 \%$. Já as áreas antrópicas, que eram de $18 \%$ em 1985, passaram para 12\% em 1996 e para 18\% em 2017 (Figura 3G). Ou seja, mesmo após a criação da APA, as áreas antrópicas ainda apresentaram crescimento.

Esta APA, segundo Zanatto (2018), possui uma importância ecológica na região, com uma rica biodiversidade e geodiversidade com potencial de exploração pela comunidade local, desde que geridas de maneira consciente. $\mathrm{O}$ autor chama a atenção que, para manter a qualidade ambiental e os atributos de conservação preservados, são necessárias estratégias para que a população participe da gestão e do processo de tomada de decisão da Unidade de Conservação.

A participação da população, inclusive, é prevista no Art. $15, \S 5^{\circ}$, da Lei $n^{\circ} 9.985$, de 18 de julho de 2000, a qual institui o SNUC (BRASIL, 2000). Nesta, é informado que a categoria de Uso Sustentável APA disporá de um Conselho constituído por representantes da população residente, de organizações da sociedade civil e dos órgãos públicos, sendo presidido pelo órgão responsável por sua administração. Uma das competências deste Conselho é acompanhar a elaboração, implementação e revisão do plano de manejo (BRASIL, 2002), documento mediante o qual se estabelece o zoneamento e as normas que devem presidir o uso da área e o manejo dos recursos naturais de uma UC (BRASIL, 2000).

Neste aspecto, não obstante a dificuldade em se encontrar informações sistemáticas, nos órgãos gestores e portais de consulta à legislação, relacionadas à implantação ou ao exercício destes, vale ressaltar que seis APAs aqui avaliadas (João Leite, dos Pireneus, da Serra das Gales e da Portaria, da Serra Dourada, da Serra Geral de Goiás e Serra da Jiboia) não possuem 
Conselho, o que pode estar influenciando na dinâmica territorial, especificamente quando observado o período após a publicação da Lei que institui o SNUC.

Segundo Santos e Nunes (2015) e Garcia et al. (2011), a não efetivação de planos de manejo e a falta de uma gestão administrativa dentro das UCs de uso sustentável ocasionam um declínio no ordenamento e fiscalização do uso da terra, que pode ser evidenciado por atividades antrópicas incompatíveis em áreas que deveriam estar destinadas a preservação. Logo, são necessários mecanismos orientando as atividades produtivas de forma a conter degradação dos recursos naturais e para um melhor ordenamento do uso da terra.

Considerando o percentual ocupado pela cobertura de Cerrado do início ao fim dos períodos avaliados, das 14 APAs estudadas, oito tiveram redução neste quantitativo, 3 aumentaram e 3 mantiveram os mesmos valores. No entanto, embora as APAs, em sua maioria, tenham perdido área de Cerrado, o percentual se encontra abaixo dos valores do bioma, 1,1\% ao ano (KLINK e MACHADO, 2005), e do estado de Goiás, 5,3\% de vegetação ao ano (BROCHADO, 2014).

As maiores modificações ocorreram nos primeiros períodos avaliados, havendo redução, na maioria das APAs, ao longo dos demais períodos. Além disso, observou-se que as atividades agropecuárias se mostraram como o principal agente de conversão do ambiente natural dentro das APAs. Em algumas APAs, no entanto, as áreas propícias para essas atividades apresentam certa limitação, seja pelo tipo solo ou relevo (MOTTA et al., 2002; MARTINS et al., 2007; COUTO JUNIOR et al., 2010; NEVES et al. 2017), o que justifica a redução das taxas de conversão ao longo dos anos estudados.

Concomitante às alterações no uso e cobertura da terra, as APAs estão sujeitas a outros tipos de pressão, como incêndios, caça, coleta de espécies nativas, erosão, assoreamento, efeito de borda, alterações microclimáticas, invasão de espécies vegetais e animais exóticos, poluição dos solos e recursos hídricos por agrotóxicos utilizados na agricultura, atropelamento de animais, o que põe em risco a sua própria existência, conforme observado por Silva et al. (2010).

\section{CONCLUSÃO}

As análises multitemporais indicaram que mais da metade das APAs estudadas tiveram suas áreas de cobertura de Cerrado suprimidas no período observado. No entanto, deve-se levar em consideração que existe uma imprecisão inerente a boa parte das metodologias envolvendo 
sensoriamento remoto e cartografia. No caso dos dados provenientes do MapBiomas, a acurácia global é de $75,4 \%$.

Alguns fatores físicos podem estar auxiliando no papel conservacionista das APAs, a partir da limitação que o tipo de solo ou relevo, por exemplo, podem ocasionar. Outros fatores (e.g. políticos, culturais, econômicos), associados ao plano de manejo, podem viabilizar o uso sustentável das APAs, sobretudo a partir da existência de um diálogo entre o sistema produtivo, a população e o governo.

De modo geral, observando a menor restrição ao uso, próprio à categoria da UC, é possível afirmar que as APAs estão cumprindo com o seu objetivo de conservação e preservação do meio ambiente, aliado ao uso sustentável dos recursos naturais.

Por fim, este tipo de estudo torna-se relevante para a compreensão da dinâmica de perda de área de Cerrado em Unidades de Conservação, podendo auxiliar os gestores, produtores e a sociedade civil em geral na elaboração de políticas públicas para a gestão dos recursos naturais, além de gerar conhecimento científico sobre o bioma Cerrado.

\section{REFERÊNCIAS}

ALVES, D. B.; PÉREZ-CABELlO, F.; CAMBRAIA, B. C.; BONADEU, F.; SILVEIRA, A. L. P. Análise multitemporal de áreas afetadas pelo fogo no enclave de cerrado do Parque Nacional dos campos amazônicos utilizando sensoriamento remoto e trabalho de campo. Geografia, Ensino \& Pesquisa, v. 22, e18, p. 01-24.

BRANNSTROM, C.; JENPSON, W.; FILIPPI, A. M.; REDO, D; XU, Z.; GANESH, S. Land change in the Brazilian savanna (Cerrado), 1986-2002: comparative analysis and implication for land-use policy. Land Use Policy, v. 25, p. 579-595, 2008.

BRASIL, Ministério do Meio Ambiente. Mapeamento do uso e cobertura do Cerrado: Projeto TerraClass Cerrado. 2015. Disponível em: http://www.dpi.inpe.br/tccerrado/download.php. Acesso em: 01 abr. 2016.

BRASIL. Lei $\mathbf{n}^{\mathbf{0}}$ 9.985, de 18 de julho de 2000. Regulamenta o art. 225, § 1o, incisos I, II, III e VII da Constituição Federal, institui o Sistema Nacional de Unidades de Conservação da Natureza e dá outras providências. Disponível em: http://www.planalto.gov.br/ccivil_03/leis/19985.htm. Acesso em: 12 mai. 2019.

BRASIL. Lei $\mathbf{n}^{\circ}$ 4.340, de 22 de agosto de 2002. Regulamenta artigos da Lei no 9.985, de 18 de julho de 2000, que dispõe sobre o Sistema Nacional de Unidades de Conservação da 
Revista de Geografia (Recife) V. 37, No. 2, 2020

Natureza - SNUC, e dá outras providências. Disponível em: http://www.planalto.gov.br/ccivil_03/decreto/2002/D4340.htm. Acesso em: 14 jun. 2020.

BROCHADO, M. M. C. Análise de cenário de desmatamento para o estado de Goiás. Trabalho de Conclusão de Curso (Graduação em Engenharia Ambiental) - Universidade de Brasília, 2014.

CARVALHO, F. M. V.; DE MARCO, P.; FERREIRA JUNIOR, L. G. The Cerrado into-pieces: Habitat fragmentation as a function of landscape use in the savannas of central Brazil. Biological Conservation, v. 142, p. 1392-1403, 2009.

COUTO JUNIOR, A. F; SOUZA, V. V; CARVALHO JUNIOR, O. A; MARTINS, E. S; SANTANA, O. A; FRETAS, L. F; GOMES, R. A. T. Integração de parâmetros morfométricos e imagem ASTER para a delimitação das fitofisionomias da Serra da Canastra, Parque Nacional da Serra da Canastra, MG. Revista Brasileira de Geomorfologia, v. 11, n. 1, 2010.

DURIGAN, G.; MELO, A. C. G.; MAX, J. C. M.; BOAS, O. V.; CONTIERI, W. A.; RAMOS, V. S. Manual para recuperação da vegetação de cerrado. 3. ed. rev. e atual. São Paulo: SMA, 2011. 19 p.

DIAS, L. T.; WALDE, D. H. Modelagem da dinâmica espacial do uso e ocupação do solo na bacia hidrográfica do Lago Paranoá-DF. Revista Brasileira de Cartografia. v. 65, n. 1, p. 7794, 2013.

FERREIRA, L. C. G.; ALMEIDA, M. G. Usos e conflitos na APA do Pouso Alto (GO): uma abordagem sobre a percepção dos atores locais de Colinas do Sul e Cavalcante. Ateliê Geográfico, v. 8, n. 1, p.215-230, 2014.

FORTES, P.T.F.O; OLIVEIRA, G.I.M; CREPANI, E.; MEDEIROS, J.S. Geoprocessamento aplicado ao planejamento e gestão ambiental na Área de Proteção Ambiental de Cafuringa, Distrito Federal Parte 1: processamento digital de imagens. In: Anais XIII Simpósio Brasileiro de Sensoriamento Remoto, Florianópolis, Brasil, INPE, p. 2605-2612, 2007

GARCIA, F. N.; FERREIRA, L. G.; LEITE, J. F. Áreas Protegidas no Bioma Cerrado: fragmentos vegetacionais sob forte pressão. In: Anais XV Simpósio Brasileiro de Sensoriamento Remoto - SBSR, Curitiba, PR, Brasil, INPE, p .4086, 2011.

GOIS, L. F. Avaliação da paisagem das bacias hidrográficas que compõem a Área de Proteção Ambiental do Planalto Central. 2017. 34f. Trabalho de Conclusão de Curso (Bacharelado em Gestão Ambiental) - Universidade de Brasília, Planaltina-DF, 2017. 
JANSSEN, L. L. F.; VAN DER WEL, F. J. M. Accuracy assessment of satellite derived landcover data: a review. Photogrammetric Engineering \& Remote Sensing, v. 60, n. 4, p 419426, 1994.

JEPSON, W. A disappering biome? Reconsidering land-cover change in the Brazilian savanna. The Geographical Journal, v.171, n.2, p. 99-111, 2005.

KLINK, C. A.; MACHADO, R .B. A conservação do Cerrado Brasileiro. Megadiversidade, v.1, n.1, p-147-155,2005.

MACHADO, E. G. B.; IMAÑA-ENCINAS, J.; RIBEIRO, G. S.; SANTANA, O. A. Índice de vegetação da diferença normalizada da área de proteção ambiental Gama - Cabeça-de-Veado, Brasília. Revista Brasileira de Ciências Agrárias, v.3, n.4, p.332-336, 2008.

MARTINS, E. S; CARVALHO JUNIOR, O. A; VASCONCELOS. V; COUTO JUNIOR, A. F; OLIVEIRA, S. N; GOMES, R. A. T; REATTO, A. Relação Solo-Relevo em Vertentes Assimétricas no Parque Nacional Serra dos Órgãos, RJ. Revista Brasileira de Geomorfologia, $\mathrm{n}^{\circ} 1$, p. 45-62, 2007.

MIRANDA, S. A. M. Uso e ocupação do solo na APA das nascentes do Rio Vermelho: Conflito Socioambiental em Mambaí - GO. Monografia (Bacharelado em Geografia), Universidade de Brasília, 2016.

MMA - Ministério do Meio Ambiente. Download de dados geográficos. Disponível em: http://mapas.mma.gov.br/i3geo/datadownload.htm. Acesso em: 12 mai. 2019.

MMA - Ministério do Meio Ambiente. O Bioma Cerrado. Disponível em: http://www.mma.gov.br/biomas/cerrado. Acesso em: 12 mai. 2019.

MOTTA, P. E. F; CARVALHO FILHO, A; KER. J. C; PEREIRA, N. R; CARVALHO JUNIOR, W; BLANCANEAUX, P. Relações solo-superfície geomórfica e evolução da paisagem em uma área do Planalto Central Brasileiro. Pesquisa Agropecuária Brasileira, Brasília, v. 37, n. 6, p. 869-878, 2002.

MYERS, N.; MITTERMEIER, R. A.; MITTERMEIER, C. G.; FONSECA, G. A. B. \& KENT, J. Biodiversity Hotspots for Conservation Priorities. Nature, v. 403, p. 853-8, 2000.

NEVES, G; SENA-SOUZA, J. P.; VASCONCELOS, V.; MARTINS, E. S.; COUTO JUNIOR, A. F. Dinâmica da cobertura da terra do Distrito Federal dentro de suas unidades geomorfológicas. Sociedade \& Natureza, v. 29, n. 3, p. 387-400, 2017.

OLSON, D.M.; DINERSTEIN, E.; WIKRAMANAYAKE, E. D. et al. Terrestrial Ecoregions of the World: A New Map of Life on Earth. BioScience, v. 51, n. 11, 2001. 
PROJETO MAPBIOMAS - Coleção 3 da Brazilian Land Cover \& Use Map Series. Disponível em: http://mapbiomas.org/. Acesso em: 02 fev. 2019.

SALA, E. O.; CHAPIN III, F. S.; ARMESTO, J. J. Global Biodiversity Scenarios for the Year 2100. Science, v. 287, p.1770-1774, 2000.

SALMONA, Y. B.; RIBEIRO, F. F.; MATRICARDI, E. A. T. Parques "no papel” conservam? o caso do parque dos Pireneus em Goiás. Boletim Goiano de Geografia, v. 34, n. 2, p. 295 $310,2014$.

SANO, E. E.; ROSA, R.; BRITO, J. L. S.; FERREIRA, L. G. Mapeamento semidetalhado do uso da terra do Bioma Cerrado. Pesquisa Agropecuária Brasileira, v.43, n.1, p.153-156, 2008. SANO, E. E.; ROSA, R.; BRITO, J. L.; FERREIRA, L. G. Land cover mapping of the tropical savanna region in Brazil. Environmental Monitoring and Assessment, v. 166, p.113-124, 2010.

SANO, E. E.; DAMBRÓS, L. A.; OLIVEIRA G. C.; BRITES, R. S. Padrões de cobertura de solos do Estado de Goiás. In: Ferreira Júnior, L. G. (Eds.) Conservação da biodiversidade e sustentabilidade ambiental em Goiás: prioridades, estratégias e perspectivas. Goiânia: UFG, p. 76-93, 2006.

SANO, E. E.; FERREIRA, L. G.; ASNER, G. P.; STEINKE, E. T. Spatial and temporal probabilities of obtaining cloud-free Landsat images over the Brazilian tropical savanna. International Journal of Remote Sensing, v. 28, n. 12, p. 2739-2752, 2007.

SANTOS, A. M. S.; ROMÃO, P. A. Estudo multitemporal e alteração na paisagem na região do distrito de Luiz Alves, município de São Miguel do Araguaia - GO, a partir de método indireto, sensoriamento remoto. Geografia, v. 16, n. 2, 2007.

SANTOS, A.C.; FERREIRA, M. E.; CARVALHO, A. R.; MACHADO, L. E. G.; PONTES, M. N.; CARAMORI, S. S. Sensoriamento remoto aplicado ao manejo de quelônios de água doce no Rio Araguaia, estado de Goiás. In: Anais XV Simpósio Brasileiro de Sensoriamento Remoto - SBSR, Curitiba, PR, Brasil, INPE, p.3079, 2011.

SANTOS, S. A.; NUNES , F. G.; SANTOS. A. M. Intensidade dos Processos Antropogênicos no Entorno do Reservatório do Ribeirão João Leite - Goiás - Brasil. Revista do Departamento de Geografia, v. 36, p.63-76, 2018.

SANTOS, S.A.; NUNES, F.G. Mapeamento do conflito de uso legal da terra nas unidades de conservação (UCs) da Reserva da Biosfera do Cerrado: nordeste de Goiás. In: Anais XVII 
Simpósio Brasileiro de Sensoriamento Remoto - SBSR, João Pessoa-PB, Brasil, INPE, p. 0933, 2015.

SILVA, D. A.; PAVÃO, M.; KANASHIRO, M. M.; DELATERRA, M. M. Uso da terra no entorno da Estação Ecológica de Itapeva, São Paulo, Brasil. In: Anais VI Seminário Latino Americano de Geografia Física/ II Seminário Ibero Americano de Geografia Física Universidade de Coimbra, 2010.

SILVA, L. R.; SANO, E. E. Análise das imagens do satélite RapidEye para discriminação da cobertura vegetal do bioma Cerrado. Revista Brasileira de Cartografia, Rio de Janeiro, v. 68, n. 7, p. 1269-1283, Jul/Ago/2016.

SOUSA, S. B. Impactos da implantação da barragem no ribeirão João Leite sobre a oferta de hortifruti na grande Goiânia. Boletim Goiano de Geografia, v.33, n. 2, p. 155-176, 2013.

STEFFEN, W.; RICHARDSON, K. ROCKSTROM, J. et al. Planetary boundaries: Guiding human development on a changing planet. Science. v. 347, 2015.

TEIXEIRA, C. O desenvolvimento sustentável em unidade de conservação: a "naturalização" do social. Revista Brasileira de Ciências Sociais, v. 20, n. 59, 2005.

UICN, Protected areas and demographic change: planning for the future. Gland, Switzerland. IUCN, 1992.

ZANATTO, V. G. Avaliação da Efetividade de Gestão de Três Unidades de Conservação do Nordeste Goiano. Dissertação de Mestrado, Universidade de Brasília, 2018.

ZARDINI, F. P. F.; SOUZA, J. C.; MARTINS, P. T. A. Meio físico e patrimonialização de áreas: elementos para a conservação do bioma Cerrado no Norte Goiano? Acta Geográfica, v. 10, p. 1-16, 2016. 